\title{
Análise Exploratória Espacial de Indicadores de Desenvolvimento Socioambiental: um olhar sobre a região metropolitana de Belo Horizonte.
}

\author{
Max Paulo Rocha Pereira - Doutorando em Geografia pela UFMG \\ arquivosmaxpaulo@gmail.com \\ Bárbara Alves Nascimento - Graduanda em Geografia pela UFMG. \\ alvesbarbara620@gmail.com \\ Guilherme Figueira Gomes Augusto - Graduando em Geografia pela UFMG. \\ gfgaugusto@gmail.com
}

\section{Resumo}

Em Belo Horizonte, o processo de metropolização começou a ocorrer na década de 1940, influenciado pelo crescimento industrial e imobiliário das cidades vizinhas. A dinâmica metropolitana é complexa pela grande influência que a centralidade exerce, concentrando no município central um número maior de recursos e esforços. Por esse motivo, o presente trabalho traz para discussão a forma como as características estruturais, econômicas, sociais e ambientais se dispõem na região metropolitana de Belo Horizonte (RMBH), possibilitando entender os resultados dessa dinâmica centro-periferia. A partir da seleção dos índices que seriam utilizados para avaliar as características, foi feita uma subdivisão em fatores sociais e ambientais, e através da utilização do Índice de Moran a espacialização da autocorrelação dos fatores ao longo da RMBH ficou mais clara e didática. Com base nisso os diferentes índices mostraram diferentes resultados em cada cidade, uns sendo insignificantes e outros correlacionados, indicando deficiências estruturais passíveis de mudanças.

Palavras-Chave: Autocorrelação espacial, Índice de Moran, Belo Horizonte, Metropolização.

\begin{abstract}
In Belo Horizonte, the metropolization process started on the 1940 decade, influenced by the industrial and real property development among neighboring cities. The metropolitan dynamics is complex due to the centrality influence, creating a concentration of resources and efforts on the main city. Therefore, this work brings to discussion the way structural, economic, social and environmental characteristics dispose over the Região Metropolitana de Belo Horizonte (RMBH), making it possible to understand this core-periphery dynamic results. From the indexes selection that would be used to evaluate those characteristics, a subdivision of social and environmental factors was made, and throughout Moran's I the autocorrelation of those factors over RMBH became clearer and more didactic. Based on this the different indexes showed
\end{abstract}


different results in each city, some being insignificant and other correlated, indicating structural deficiencies liable of changes.

Palavras Chave: Autocorrelation, Moran's I, Belo Horizonte, Metropolization.

\section{Introdução}

A urbanização brasileira é um fenômeno que ganhou força no mundo todo, se expressando mais fortemente como consequência da expansão do capitalismo global que se deu a partir do final da guerra fria recente. No Brasil, esse processo teve início na década de 1940 e se intensificou na década de 1970. Com advento da globalização e da consolidação de uma sociedade industrial as cidades passam então a receber fluxos de serviços, pessoas e informações sem que estes espaços estejam estruturados para as demandas essas novas demandas.

Embora exista um caráter global na urbanização, esse fenômeno acontece de forma e escala diferente. Nos países da periferia do capitalismo como é o caso do Brasil, esta dinâmica de produção do espaço se deu de forma acelerada e desordenada se configurando, no entanto, como um processo permanente e irreversível (SANTOS, 2009).

Nessa perspectiva para além do crescimento urbano dentro dos seus limites legais, tem com a industrialização também a possibilidade de formação de centralidades, ou seja, municípios que exercem uma influência específica ou difusa em seus vizinhos, sendo esse fenômeno responsável, por exemplo, pela formação das regiões metropolitanas e consequentemente da metrópole.

Queiroz e Brasil (2009) destacam que a dinâmica da metropolização, se constitui essencialmente como uma relação centro-periferia, fazendo com que os municípios sofram um processo que tem uma lógica própria e que os une de maneira indissociável, criando problemas comuns que não podem ser resolvidos por uma soma de ações locais, mas de forma coletiva. O grande desafio da questão metropolitana é a criação de um modelo jurídico institucional capaz de gerir democrática e eficazmente a região metropolitana.

Uma das consequências dessa relação é a centralização de esforços e recursos na metrópole, sendo que esse esforço pode ir se diluindo à medida que a municipalidade se afasta de seu centro, correndo o risco assim da metropolização gerar bolsões de segregação socioespacial e ambiental nos limites da região metropolitana. 
Belo Horizonte, capital mineira, é uma dessas centralidades. Passos (2016) considera que o processo de planejamento e a concepção desse município deve ser analisado a luz do seu tempo, numa visão de valorização do racional e para uma capital que se pretendia modelo dentro do estado republicano.

Esse planejamento urbano, rígido e extremamente funcionalista, não tardou por falhar, a industrialização, as migrações, o preço da terra, dentre outras variáveis fizeram com que cada vez mais os limites estabelecidos fossem rompidos pela ocupação humana. Moura (2012) ressalta que esse fenômeno de expansão urbana descontrolado resulta na produção de cidades dispersas e fragmentadas que se configuram fundamentalmente através do espraiamento físico do território ocupado, densificando os fluxos de mercadorias, o remanejamento de pessoas e a criação de novas centralidades sem que as mesmas tenham infraestrutura para assumir esse papel regional.

Assim Belo Horizonte, considerando os seus 100 primeiros anos de existência, foi se transformando de um projeto de capital idealizado e desenhado em uma cidade industrial e consequentemente em uma metrópole periférica que atualmente expandiu sua área de influência na forma de uma urbanização dispersa, extensiva, em direção a um largo entorno regional que transcende os limites formais da região metropolitana e seu colar (COSTA, 2012).

Criada em 1973 pela Lei complementar $\mathrm{n}^{\circ} 14$ a região metropolitana de Belo Horizonte $(\mathrm{RMBH})$ possuía originalmente 14 municípios passando por diversas atualizações até que em 2002 com a entrada do município de Itatiaiuçu a RMBH assumiu o arranjo espacial que preserva até hoje.

Para entender melhor como se da à distribuição espacial das características que se relacionam com a estrutura e a qualidade de vida das populações residentes nos municípios dessa região metropolitana este trabalho se debruçou sobre uma análise exploratória espacial de indicadores de desenvolvimento socioambiental desses municípios, possibilitando de forma simples e eficaz compreender a magnitude de possíveis auto correlações entre as características espaciais da metrópole e sua região de influência.

\section{Análise Exploratória dos Dados}

A análise exploratória de dados é muitas vezes preterida ou dispensada em trabalhos que buscam identificar ou entender melhor dinâmicas espaciais. Isso porque 
existe uma ideia de que tais estudos são dispensáveis, no entanto, os mesmos apresentam um relevante potencial de demonstrar relações dependência espacial e ou de auxiliar na escolha de modelos estatísticos mais robustos que sejam mais adequados ao tipo de evento que ali se expressa.

Essa análise pode então, ser utilizadas a partir de informações espacialmente explicitas com o objetivo de compreender a importância de seu arranjo e dos fenômenos que se nele se expressam possibilitando interpretações acerca desses sistemas. Dentro dessa perspectiva Bailey e Gattrel (1995) consideram também como seu objetivo o aprofundamento na compreensão dos processos, a avaliação de evidências de hipóteses a ele relacionadas e também a previsão de valores em áreas onde as observações não estão disponíveis.

Embora parta de um Câmara et al. (2004, p.4) verificam que os procedimentos de análise espacial lidam tanto com dados ambientais, como com os dados socioeconômicos. Em ambos os casos, a análise espacial é composta por um conjunto de mecanismos encadeados cuja finalidade é a escolha de um modelo inferencial que considere explicitamente os relacionamentos espaciais presentes no fenômeno. Assim, o seu aspecto fundamental é mensurar as propriedades e seus relacionamentos levando em conta, a localização espacial do fenômeno em estudo de forma explicita, ou seja, incorpora o espaço a análise que se deseja realizar.

Dentre as muitas possibilidades de análises espacial Câmara et al. (2004b) destacam, por exemplo, as regiões de outliers tanto com seu conjunto dos dados, como também em relação aos seus vizinhos. Possibilitando a identificação da estrutura de correlação espacial que seja mais adequada aos dados em análise.

Diante dessas perspectivas neste trabalho utilizou-se como indicador global de auto correlação espacial o Índice de Moran amplamente utilizado e descrito por diversos autores como um método que possibilita uma compreensão dos processos e sua relação com o espaço através da estimativa de quanto do valor de uma variável que se expressa em uma determinada região é dependente dos valores dessa mesma variável na sua vizinhança (Santos e Raia Junior, 2006, p.100; Câmera et. al., 2005).

Além do índice de Moran, outras análises foram realizadas, no entanto, importante assumir o objetivo das mesmas no contexto desse artigo que procurou analisar possível relação de dependência entre variáveis sociais e ambientais dos municípios com seus vizinhos na região metropolitana, tendo como norte as seguintes perguntas: 
É possível identificar dependência espacial significativa entre os municípios da região metropolitana de Belo Horizonte para as variáveis aqui observadas?

Como se compartam tais variáveis à medida que aumenta a distância espacial dos municípios com a metrópole?

\section{Materiais e Métodos}

A área de estudo compreende os 34 municípios integrantes da região metropolitana de Belo Horizonte (Figura 1).

Figura 1: Região Metropolitana de Belo Horizonte - RMBH

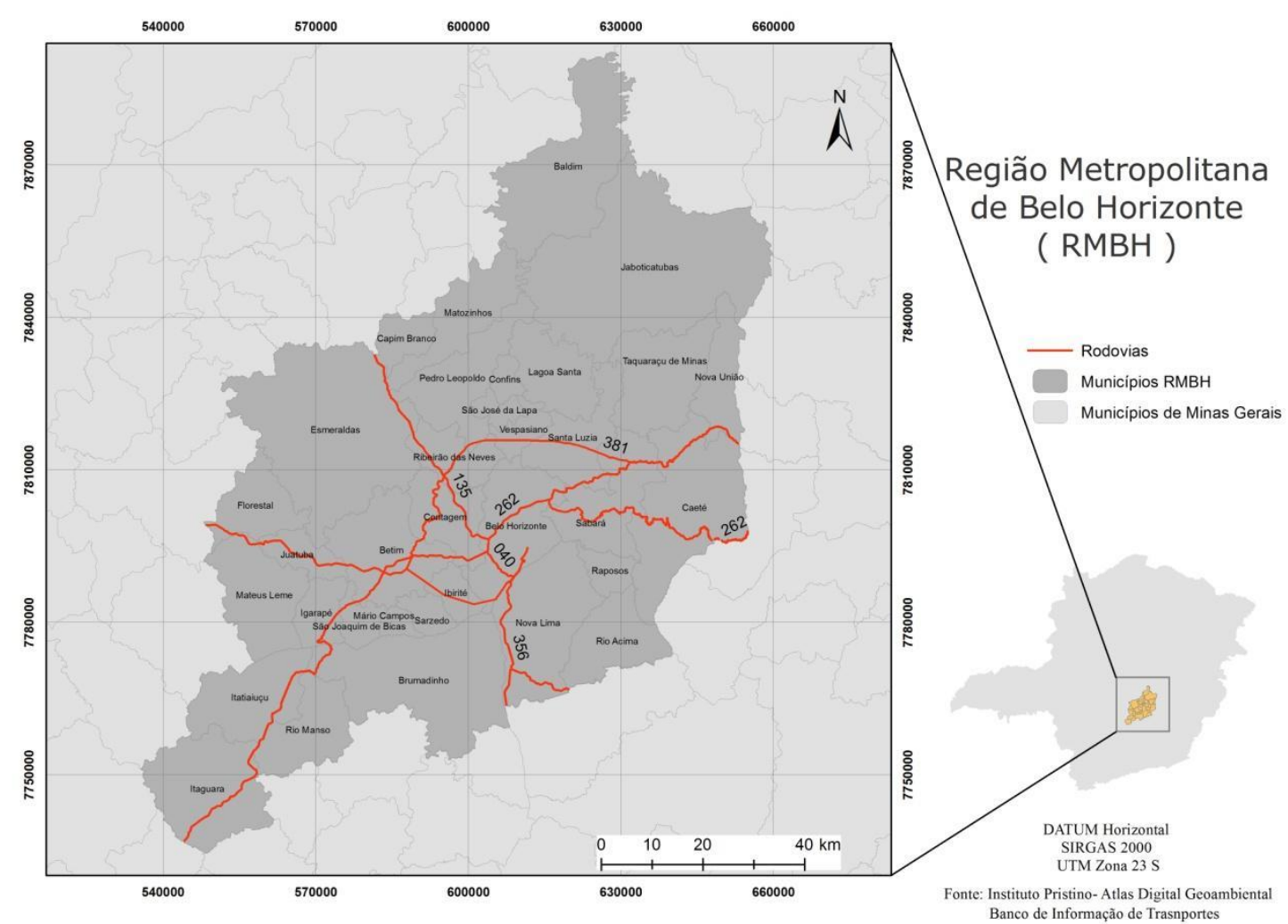

O processo de metropolização da capital mineira teve início na década de 1940 e foi fortemente influenciado pela industrialização das cidades do entorno como a inauguração da Cidade Industrial de Contagem em 1946, expansão imobiliária de Contagem e Betim, ocasionando a conurbação de Belo Horizonte com os municípios vizinhos.

Nas duas décadas seguintes a população da capital passou de 500 mil habitantes para 1 milhão e quinhentos mil, sendo que a parte mais significativa dessa migração se deu internamente ao estado de Minas Gerais (FJP/Plambel, 1974). 
Nos anos seguintes a década de 1980 o desenvolvimento da metrópole se consolida, no entanto, apresentando um padrão de adensamento população mais direcionado ao entorno, intensificando o processo de periferização e modelando o desenho espacial da região metropolitana.

Para compreender melhor as expressões desse fenômeno no espaço a metodologia aqui proposta admitiu na seleção dos indicadores socioambientais descrita na (Figura 2):

Figura 2: Estrutura metodológica

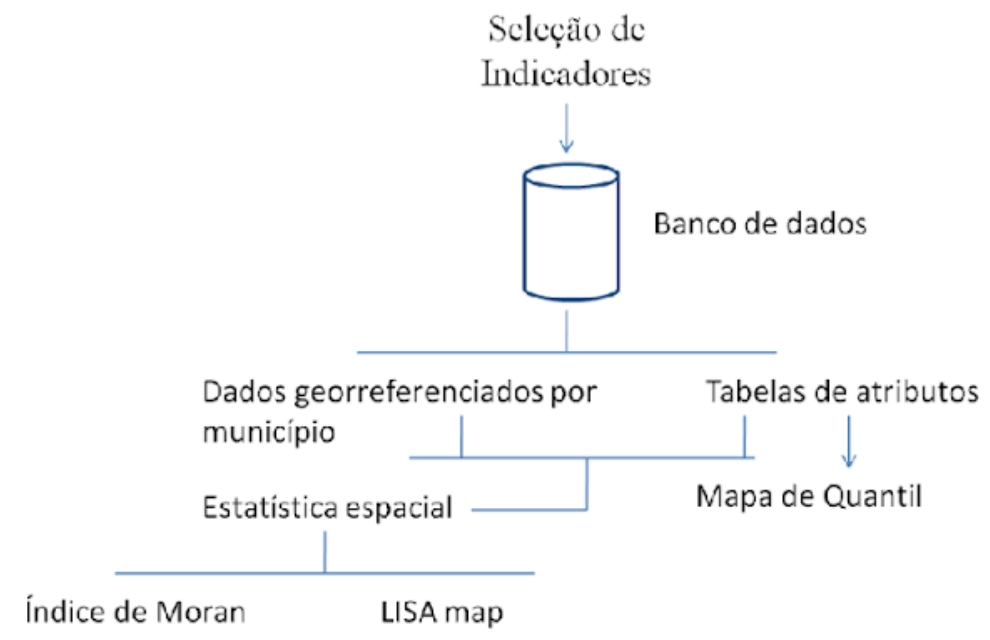

No processo de seleção dos indicadores utilizou-se o proposto pelo IBGE (2010) que estabeleceu os Indicadores de Desenvolvimento Sustentável do Brasil, sendo que para este trabalho adaptou-se os mesmos, o fator econômico passou a ser um subfator do social sendo que para o mesmo além da variável IDHM renda foi utilizado o Índice de Gini municipal com o objetivo de diminuir a distorção da desigualdade de renda.

Assim o conjunto de indicadores adotados foram divididos em 2 fatores, um representado pela dimensão social e um segundo fator representado pela dimensão ambiental e por nove subfatores descritos na tabela 1 sendo que, tais fatores foram direcionados a um ambiente SIG para alimentar o banco de dados que possibilitou a realização das análises.

Tabela 1: Variáveis selecionadas

\begin{tabular}{cll}
\hline Fatores & Subfatores & Indicadores \\
\hline \multirow{2}{*}{ Social } & Educação & $\begin{array}{l}\text { Taxa de analfabetismo da população de 15 } \\
\text { anos ou mais de idade sobre a população total } \\
\text { por município }\end{array}$ \\
\hline
\end{tabular}




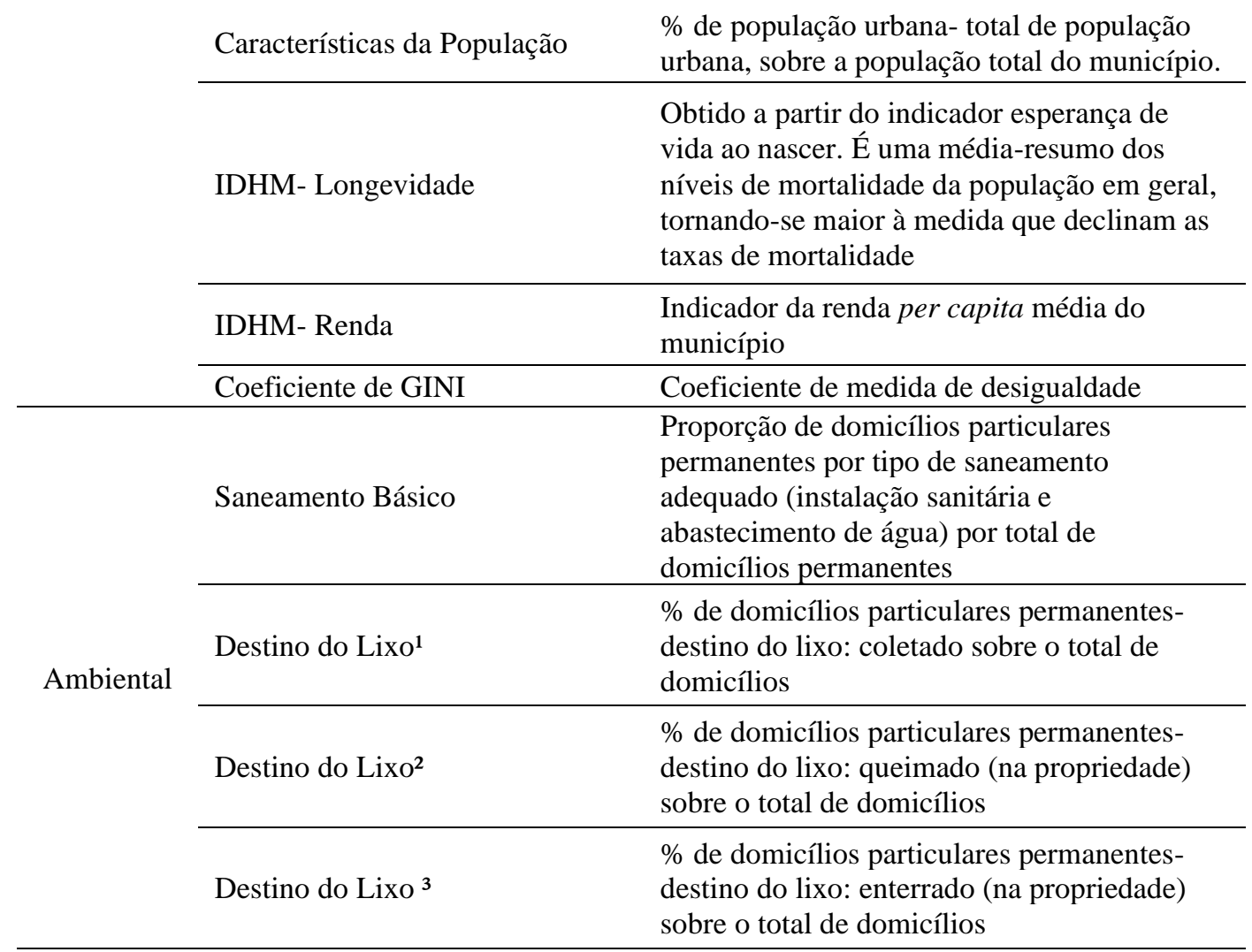

Os indicadores foram espacializados por municípios, sendo que na etapa de geoprocessamento foi utilizado o software ArcGis 10.4 onde inicialmente realizou-se o agrupamento de cada uma das variáveis através da propriedade "Symbology" da layer em análise gerando quantis a partir da divisão por quantities na categoria graduated color.

O cálculo da associação espacial global de Moran foi gerado utilizando a ferramenta Spatial Autocorrelation (Morans I) e a correlação local através da ferramenta Cluster and Outlier Analysis (Anselin Local Morans I) ambas do ArcToolbox Spatial Statistics Tools.

\section{Resultados e Discussão}

Ao se analisar os agrupamentos por quantis dos índices sociais (Figura 3) temse uma ideia de um possível arranjo espacial de características em comuns entre os municípios.

Figura 3: Agrupamento por quantis dos índices do fator social 


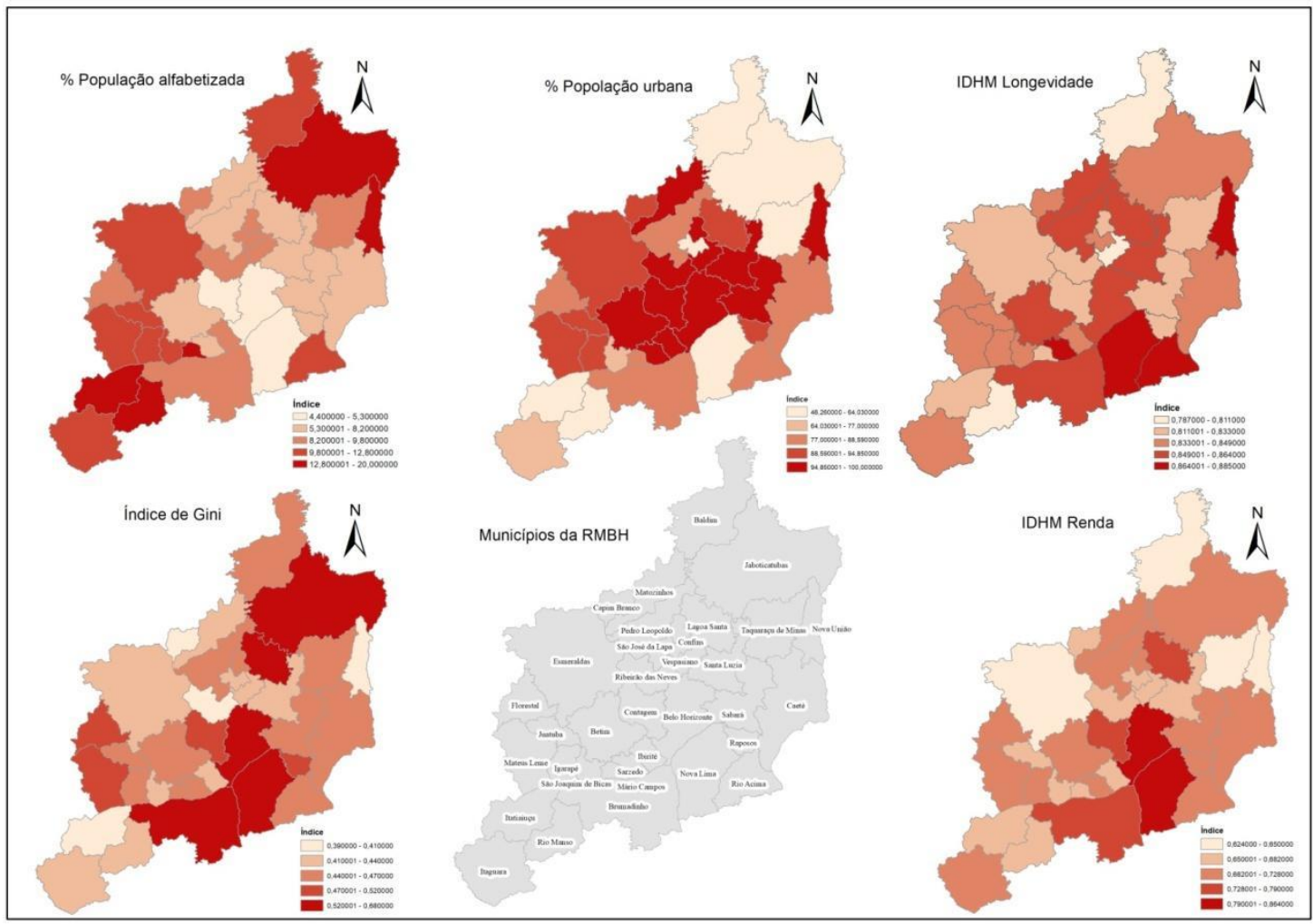

Na dimensão educação, por exemplo, observamos uma possível concentração dos menores índices de analfabetismo na capital e suas vizinhas, à medida que os municípios se afastam espacialmente da capital o índice aumenta. O contrário se observa na característica da população, uma vez que a capital e seus vizinhos apresentam a maior concentração urbana, o que era de se esperar ao considerarmos por exemplo que Belo Horizonte não possui a categoria rural na divisão do seu território e que o processo de metropolização se deu principalmente com os adensamentos e expansões urbanas dessa região.

A variável IDHM longevidade não apresenta a formação de grande agrupamento entre municípios vizinhos, podendo indicar que a expectativa de vida não é uma variável sensível para essa escala de análise. Já as variáveis IDHM Renda e Gini apresentam concentração de valores elevados na capital e seus vizinhos, demonstrando maior renda per capta nessa região, mas também maios desigualdade e concentração dessa renda, alguns municípios como Jaboticatubas, por exemplo, apresenta uma renda relativamente baixa com o agravo de uma alta desigualdade.

Já o agrupamento dos índices ambientais (Figura 4) apresentam uma maior separação da capital e seus vizinhos do restante dos municípios da região metropolitana. No indicador de saneamento básico, por exemplo, o melhor quantil é formado justamente 
pela capital e seus vizinhos. Enquanto os municípios que pertencem ao pior quantil, ou seja, pior condição de saneamento, estão localizados nas extremidades da região metropolitana com exceção de Confins que apresenta uma alta taxa de fossas sépticas e baixa coleta de esgoto.

Figura 4: Agrupamento por quantis dos índices do fator ambiental
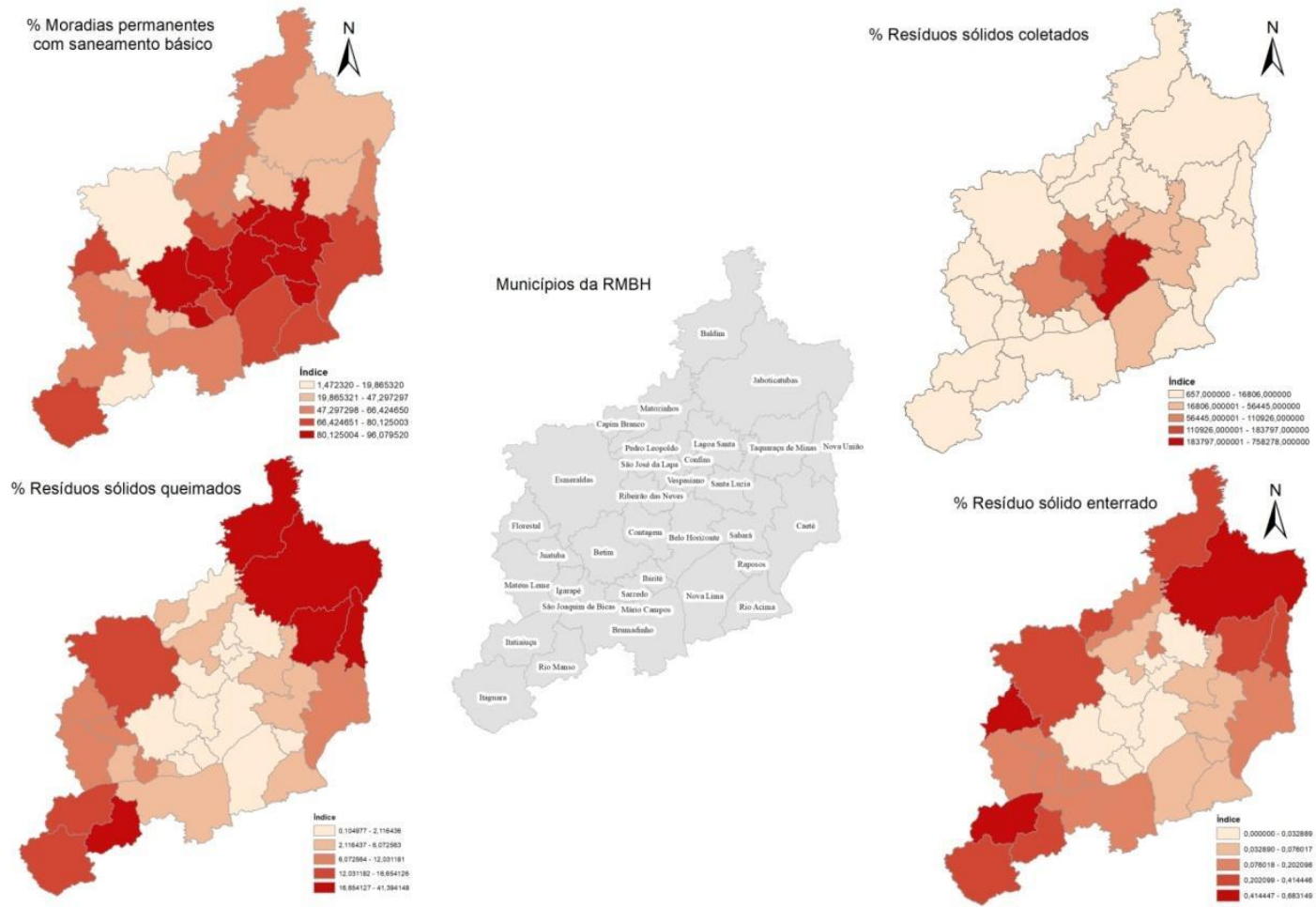

A coleta de resíduos segue uma lógica semelhante tendo a capital e seus vizinhos no melhor quantil e consequentemente uma pior condição de disposição final de resíduos sólidos nos municípios mais afastados da capital. Esse cenário pode indicar inclusive aquilo que foi indicado antes ao se considerar a priorização da metrópole em detrimento dos outros municípios, claro que essa análise deve ser realizada no âmbito da proporcionalidade, uma vez que, quando analisou-se a população urbana percebe-se que a região que mais sofre com a pressão do adensamento populacional urbano é justamente a metrópole e seus vizinhos.

O indicador de correlação espacial global I de Moran varia de -1 a 1 sendo que o valor igual a 0 indica ausência de correlação espacial e os valores próximos de 0 apresentam uma correlação espacial muito baixa. Já os valores próximos de 1 apresentam correlação espacial positiva, ou seja, a existência de um grupo com valores médios 
semelhantes aos valores médios de seus vizinhos, enquanto os números negativos próximos de -1 apresentam auto correlação espacial negativa, inversamente proporcional.

Os resultados obtidos estão apresentados na tabela 2, e demonstram não haver correlação espacial entre os indicadores observados nos municípios com exceção dos indicadores de saneamento resíduo queimado e resíduo enterrado que embora apresentem um Moran global mais próximo de 0 do que de 1 , apresentam o p-valor bem abaixo de 0,02, sendo assim a hipótese não pode ser descartada.

Tabela 2: Índice de Moran global dos indicadores analisados.

\begin{tabular}{|c|c|c|}
\hline Indicadores & I Moran Global & p Valor \\
\hline Domicílios com Saneamento & 0.21 & 0.01 \\
\hline Coletado & 0.08 & 0.03 \\
\hline Queimado & 0.42 & 0.000001 \\
\hline Enterrado & 0.41 & 0.000003 \\
\hline IDH Longevidade & -0.01 & 0.86 \\
\hline IDH Renda & 0.02 & 0.61 \\
\hline Índice de Gini & 0.01 & 0.63 \\
\hline População Urbana & 0.02 & 0.57 \\
\hline População Rural & 0.02 & 0.57 \\
\hline Taxa de Analfabetismo & 0.3 & 0.001 \\
\hline
\end{tabular}

A expressão espacial da correlação local foi representada por mapas temáticos onde cada zona identificou um par ordenado formando um clusters (Alto-Alto) onde estão os municípios que apresentam índices superiores à média (desvios positivos) e de seus municípios vizinhos com média também positivas (cluster positivo), (Baixo-Baixo) com os municípios que apresentam índices negativos e média dos vizinhos, também negativa, abaixo da média global (cluster negativo). Já as áreas de transição (outliers) são identificadas nos (Alto-Baixo) e (Baixo-Alto), sendo aquelas que representam o município, considerado a média dos seus municípios vizinhos com comportamento oposto.

Assim ao analisarmos o indicador de educação e o de características da população (Figura 5) vemos que se mantém até certo ponto o demonstrado no agrupamento de quantis. 
Figura 5: Correlação espacial local dos indicadores educação e características da população.
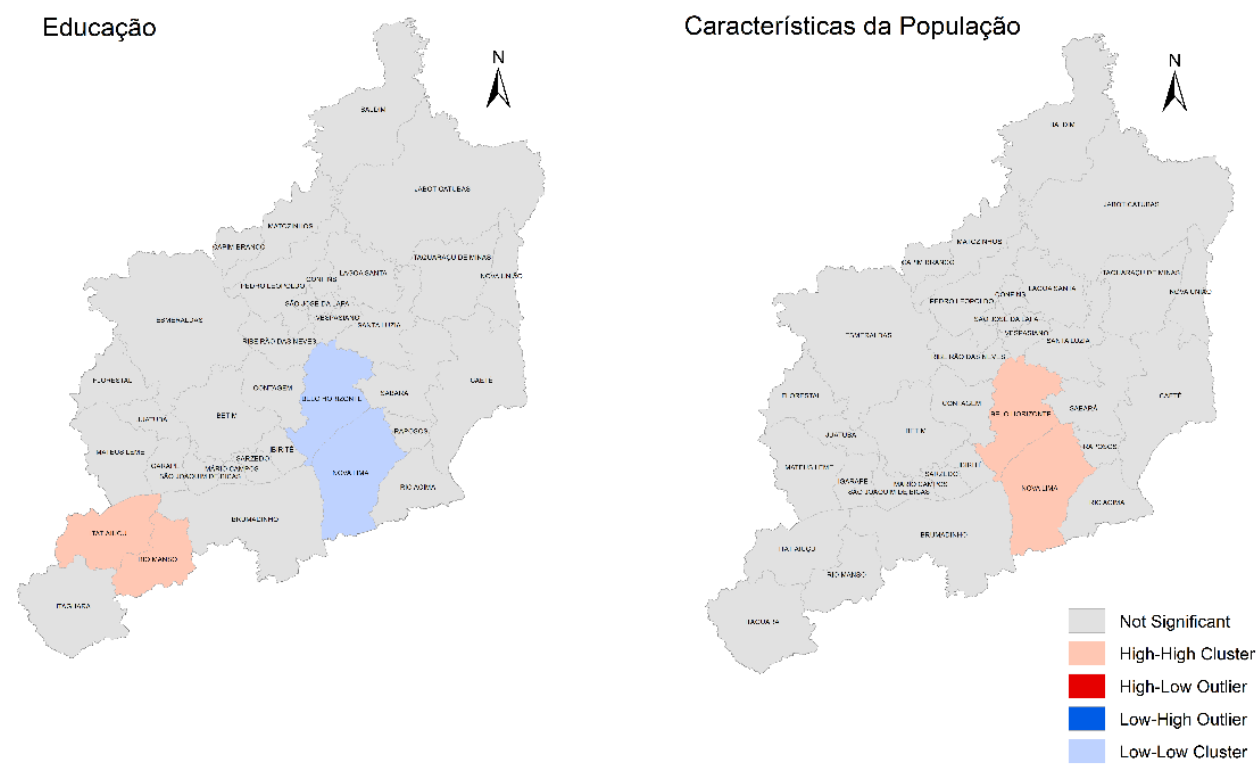

No indicador de educação observa-se que os municípios de Itatiaiuçu apresentam taxa de analfabetismo com valores médios mais altos do que de seus vizinhos, assim como o indicador de população apresenta uma taxa de população urbana baixa, mas semelhante à de seus vizinhos, o que pode indicar a necessidade de priorização de esforços para o tema educação no âmbito desses municípios.

Para os indicadores Gini, IDHM Renda e IDHM longevidade (Figura 6), observa-se a formação de um cluster de renda entre Belo Horizonte e Nova Lima que se reproduz no indicador de desigualdade Gini, demonstrando um cluster de renda média alta próximo a municípios que possui renda média alta, enquanto para longevidade observa-se dois outliers, um em nova união com uma média de esperança de vida alta diferente da média de esperança de vida de seus vizinhos, enquanto Taquaraçu de Minas observa-se o contrário. Já em São José da Lapa observa-se a média da desigualdade (Gini) acima da média da desigualdade dos municípios vizinhos, indicando uma possível maior concentração de renda.

Figura 6: Correlação espacial local dos indicadores Gini, IDHM Renda e IDHM longevidade. 

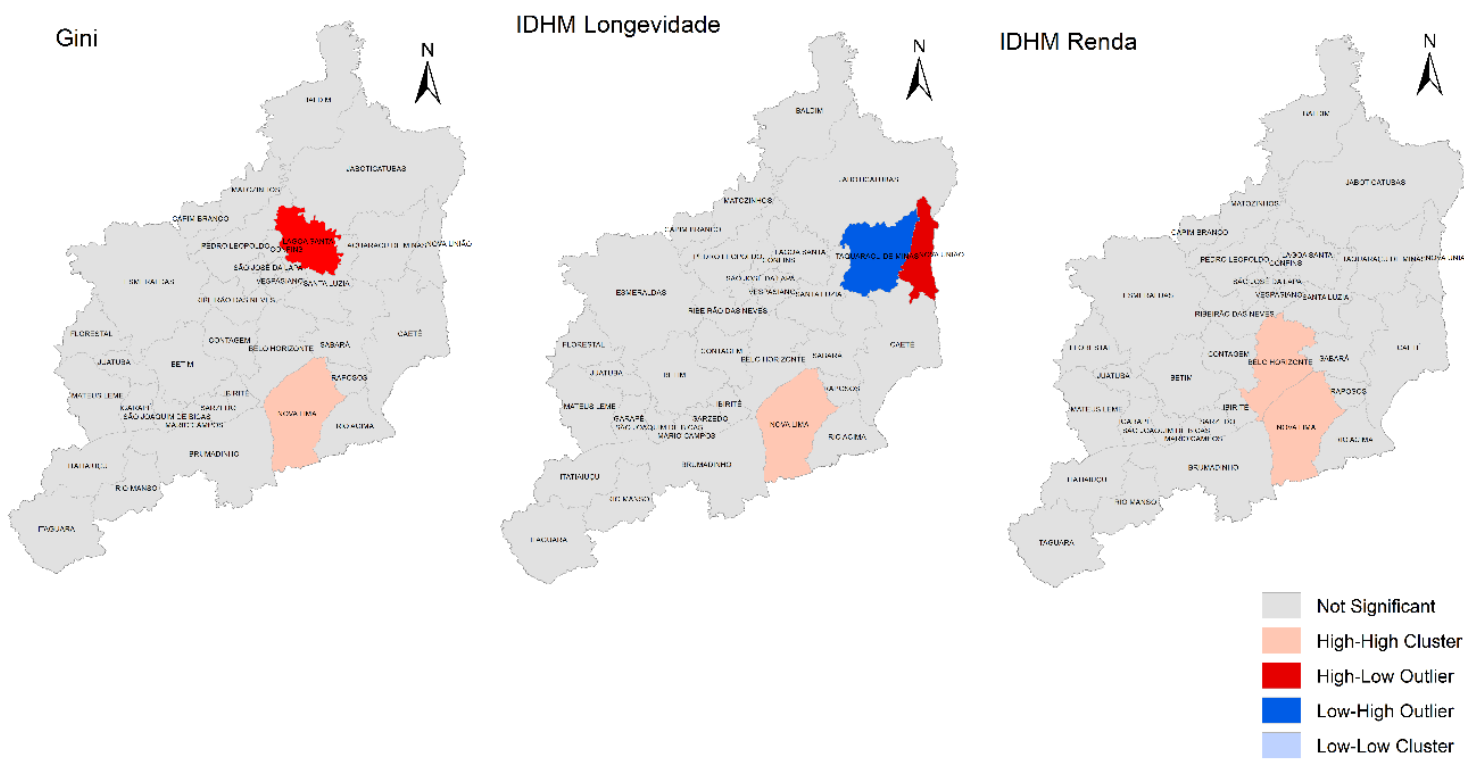

Para o indicador de saneamento (Figura 7) existe a formação de um cluster positivo, ou seja, valores médios de saneamento adequado acima dos valores médios de saneamento adequado dos vizinhos, integrando Belo Horizonte, Sabará, Contagem e Raposos, enquanto o município de Capim Branco se destaca por apresentar valores médios abaixo do de seus vizinhos, indicando uma pior condição de saneamento.

Figura 7: Correlação espacial local do indicador de saneamento. 


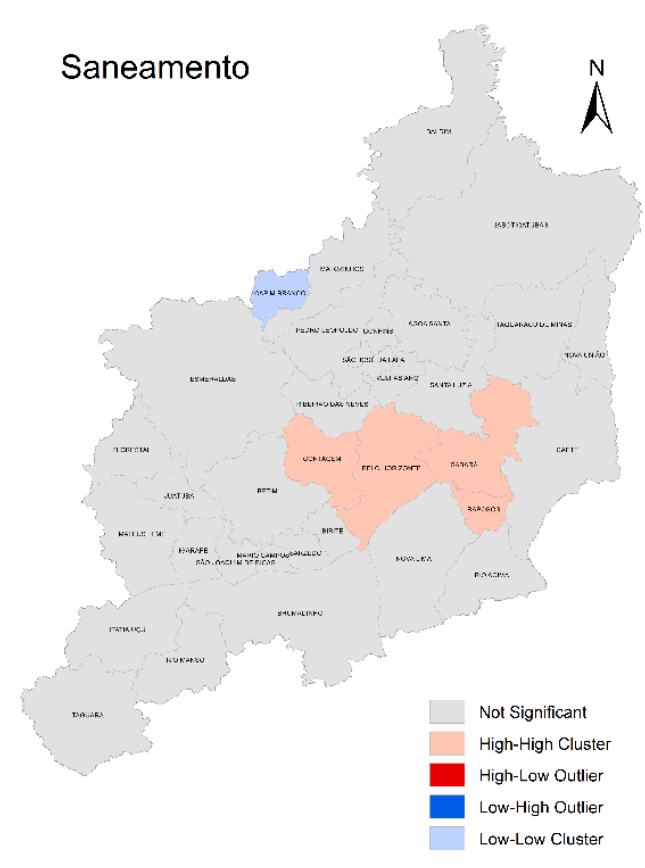

As variáveis lixo coletado, lixo queimado e enterrado (Figura 8), demonstram a relação da região metropolitana com os resíduos sólidos, sendo que as variáveis lixo queimado e lixo enterrado foram as únicas que apresentaram correlação espacial. Os municípios de Baldim e Jaboticatubas, Taquaraçu de Minas e Nova União no extremo norte da região metropolitana formam um cluster de altas médias de lixo queimado com relação aos seus vizinhos, enquanto Esmeralda, Itatiaiuçu, Rio Manso e Itaguara na extremidade sul da RMBH apresentam a média de lixo enterrado acima de seus vizinhos.

Figura 8: Correlação espacial local do indicador de lixo coletado 

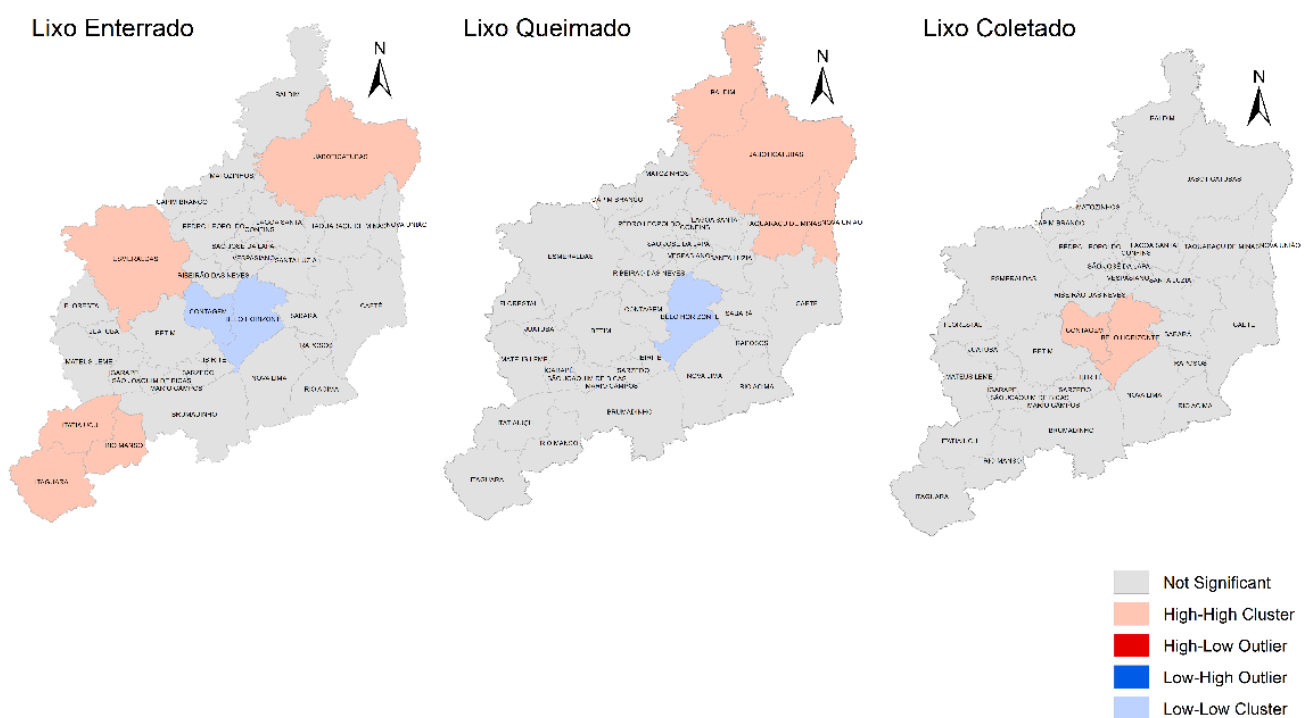

Esses dados demonstram um desequilíbrio na gestão de resíduos sólidos na $\mathrm{RMBH}$, sendo que os municípios da extremidade possuem piores condições na coleta e destinação do lixo, podendo oferecer riscos de poluição e contaminação ao solo, água e ao ar.

\section{Considerações Finais}

A análise exploratória dos dados não revelou correlação espacial entre os indicadores analisados com exceção do lixo coletado e do lixo queimado. No entanto, ela possibilitou a produção de um conjunto de tabelas e mapas que juntos caracterizam importantes aspectos da área de estudo, apontam possibilidades de análises mais robustas e favorecem a rápida visualização de necessidades específicas dos municípios.

A presença de correlação espacial entre os indicadores de lixo queimado e lixo enterrado com a formação de clusters de lixo queimado e enterrado nas extremidades norte e sul da RMBH demonstram a necessidade de se direcionar investimento para coleta adequada e destinação final ambientalmente correta desses resíduos. 


\section{REFERÊNCIAS}

BATANERO C.; ESTEPA A.; GODINO J.D. Análisis exploratorio de datos: sus posibilidades en la enseñanza secundaria. Suma, 9, 25-31. 1991.

BAILEY, T. C; GATRELL, T. C. Interactive Spatial Data Analysis. London: Prentice Hall, 1995.

CÂMARA, Gilberto; CARVALHO, Marília Sá; CRUZ, Oswaldo Gonçalves; CORREA, Virginia. Análise Espacial de Áreas. [A. do livro] Gilberto Câmara e Clodoveu Davis (org.). Introdução à Ciência da Geoinformação. INPE. São José dos Campos, 2005.

COSTA, H. S. M. (2012) E nas metrópoles, quem planeja o território? Breve contribuição ao debate a partir da experiência recente de Belo Horizonte, In A. C. T. Ribeiro e E. Limonad. (Org.). Desafios ao planejamento: produção da metrópole e questões ambientais. Letra Capital, Rio de Janeiro.

FJP/Plambel. O desenvolvimento econômico e social da Região Metropolitana de Belo Horizonte. Belo Horizonte: Fundação João Pinheiro, 1974 (Vol. II - Estrutura Econômica. 11 p.)

QUEIROZ, L. S; BRASIL, F, P, D. O NOVO ARRANJO INSTITUCIONAL DA REGIÃO METROPOLITANA DE BELO HORIZONTE COM FOCO NA PARTICIPAÇÃO EM SEU CONSELHO DELIBERATIVO. Anais do XXXIII Encontro da ANPAD. São Paulo, 2009.

SANTOS, O. R; OLIVEIRA, L. K; NÓBREGA, A. A. R; DABLANC, L. EXPANSÃo URBANA EM BELO HORIZONTE E AS IMPLICAÇÕES NO TRANSPORTE URBANO DE MERCADORIAS. Anais do $7^{\circ}$ Congresso Luso Brasileiro para o Planejamento Urbano, Regional, Integrado e Sustentável. Maceió, 2016.

SANTOS, Luciano dos; RAIA JUNIOR, Archimedes Azevedo. Análise Espacial de Dados Geográficos: A Utilização da Exploratory Spatial Data Analysis - ESDA para 
Identificação de Áreas Críticas de Acidentes de Trânsito no Município de São Carlos

(SP). Sociedade \& Natureza, Uberlândia, v.18 (35), p. 97-107, dez. 2006. 